\title{
Margaret Gibson
}

Real-Life Death:

Between Public and Private, Interior and

Exterior, the Real and the Fictional

\begin{abstract}
As most people living in affluent countries have less frequent and less direct encounters with the scenes of death of family members and others, representational culture of both real life and fictional or simulated death plays an increasing role in defining the experience of seeing and bearing witness to death. In some respects we live in both a postemotional ${ }^{1}$ and a hyperemotional society regarding how we react to and experience the deaths of others. ${ }^{2}$ Two situations reflect both emotional conditions: the phenomenon of online suicides, in which people watch someone take his or her life with little or no moral consciousness, and the intense communal processes of grief over the deaths of celebrities such as Michael Jackson that are globally mediated and refracted through camera and screen.

Through a selection of examples of death scenes, from film, television, the Internet, and literature, I focus here on the relationship between self and other, interiority and exteriority, public and private, in the experience and representation of death as scene/seen. I explore some of the ways in which the inner drama of death is represented to a viewer or reader of a cultural text and consider the boundaries, limits, and politics of
\end{abstract}

The South Atlantic Quarterly 110:4, Fall 2011

DOI 10.1215/00382876-1382321 $\quad$ (C) 2011 Duke University Press 
death representation in an era of mass commodification, consumption, and self-broadcasting media culture.

\section{The Represented Death Scene}

French historian Philippe Aries, drawing on the theatrical metaphor of a scene, reminds us of the staged nature of the deathbed setting, where the dying person plays the central role: "He presided over the affair with hardly a misstep, for he knew how to conduct himself, having previously witnessed so many similar scenes." ${ }^{3}$ The familiarity of the death scene within the lived experience of each individual from childhood to old age has not informed practices of socialization within the biographies of modern individuals and families. Aries argues that in premodern societies death had its place within family experience. Before twentieth-century medicine, a recognition and prescience of death existed more palpably because it could be the outcome of a minor affliction, such as a cold turning into pneumonia. This gave death a kind of socially acceptable and also undeniable proximity. One could not discount its possibility, its hovering potential, in events or scenarios of illness. In modern affluent societies, advances in medicine, government regulation of hygiene, human environments, and populations have widened the gap between life and death, as deadly diseases can be more easily managed or cured. While it is true that death is highly visible and much less taboo in contemporary life, the experience of witnessing death, first-hand, remains uncommon for most people in affluent societies and social classes, and is often deferred until adulthood due to longer life expectancies. The removal of death from the home and into institutions of hospital and hospice has also displaced the setting of the death scene among a broader, historically more public but localized face-to-face community of ritual and witness.

Before the twentieth century and the rise of mobile populations, large cities, and impersonal communities, death had a more communal character, and the dying person could expect his or her room to be occupied by a priest, family, friends, neighbors, and even strangers. ${ }^{4}$ In a highly mediated age, death has a public presence by proxy, by way of the camera and multimedia sites of publication and distribution. For most people in affluent societies, excluding those in health professions, witnessing death directly is minimal. Indeed for these groups and societies in late modernity, primary or early inscriptions of death imagery, including emotional and psychical impact, will be sourced predominantly from media, gaming culture, 
and other forms of popular culture. In setting up a distinction between real and fictional death scenes, I do not propose a hierarchy between the terms, such that the real underscores or is a foundation to the fictional. On the contrary, what I propose to demonstrate is how each supplements, crossreferences, or translates across the other.

Media and entertainment culture often circumscribe the scene of death according to given intelligibilities. By this I mean that death is invariably tamed and contained by genre. At the same time, clearly defined and discernible genres increasingly blur or become hybridized by new forms of media and entertainment culture. Through this process, the same images of death are translated across different media cultures and modes of delivery. In a multimedia age, all forms of media cross-reference, as stories and images are lifted out, copied, added to, and re-embedded across multiple sites and technologies (phones, DVDs, Web sites, computers). Thus while death scenes might have their origin on the Internet, they can find their way onto television news broadcasts, which in turn have Web-based broadcasts and reports.

In 2009 , for example, a front-page image in newspapers around the world and the video image on Web sites was that of Neda Soltan, a twentysix-year-old Iranian woman killed during protests in Tehran. Her death on June 20,2009 , filmed on a mobile phone camera, captured in graphic detail the massive loss of blood as her life and consciousness drained away. Indeed, a scene of death was translated into a "death scene" through the frame of the camera and the image's subsequent transportation into world media coverage and archives. This death scene inscribed and produced a double figuration of the body politic. Soltan's death and dead body marked the violent oppression of the Iranian state against civil liberty, and her death/body came to signify resistance against a corrupt, authoritarian government. However, it was not just one death scene broadcast in the media but at least two-the still image of her death and the moving image of her dying-toward-death - two different frames and temporalities of seeing and looking at a death. This woman's death is not a death scene that particularly speaks to a white, middle-class Western imagination in terms of its own biography, but it is a scene that resonates through a politics of identification with freedom and the democratic process. While the genre of documentary news reporting and news media might be judged as the most appropriate representational space for such death imagery, its locations were multiplied across print and virtual media sites. Indeed, it quickly became part of the hybridized news-entertainment genre in its circulation through publi- 
cations such as Australia's Who Weekly. Who published images of Soltan on a full page-a larger image of her alive and happy and a smaller picture of her dead. ${ }^{5}$ This single page on Soltan's death was framed within a larger segment of stories and images titled "10 Hot Pics," which also includes "Bruno Goes Global," "Chris Dodges Jail," "Sienna \& Balthazar Rebound Romp!," Robert Pattinson's New Aussie Love?," "Mayhem over Mercy: Madonna's New Malawian Daughter Arrives in London," "Celeb Baby News," "Gisele's Pregnant!" and "Dying for Democracy."

The dominant photographic image in the Who story positions Sol$\tan$ as an attractive, nontraditional Middle Eastern woman, enabling her image to be located within a narcissistic frame, that is, within a model and boundary of self-identification. She is not only "like us" (whoever this "us" is) but wants to be "like us" in her fight for democracy. The image of Soltan alive is centered, serving to make secondary, and paradoxically less recent, the photographic image and event of Soltan dead. The image of Soltan alive is thus reborn to supplant and overcome death as negative signifier-the death of democracy, the death of civil resistance, the failure of the state to murder the fight for democracy. The perspective of the dominant image also aligns and inscribes sameness rather than difference in the relationship between the image of Soltan and the viewer. The reader/viewer is also constructed as a homogenous group aligned with a mainstream Western image of femininity, that is, the unmarked universal norm. However, a third photo interrupts and complicates this reading, as it shows the image of protesters identifying with Soltan ("I am Neda") as their symbol in the struggle for freedom and democracy. Thus one has to question one's own reading or interpretive strategy as a process of circumscribing and prioritizing the meaning of the images according to certain interpretative investments that invoke the dominance of an Orientalist, Western gaze, while at the same time politically disavowing this hierarchy of identity and power. In other words, reading strategies are not innocent but produce the very effects of power that they seek to dismantle and displace.

The postmodern eclecticism of the "10 Hot Pics" effaces specificities of context, flattening out a difference of gravity in terms of diverse subject matter.? Such publication processes exemplify Fredric Jameson's critique of the cultural logic of postmodernism, where "depthlessness" abounds in a "culture of the image or the simulacrum." 8 One can also argue that this blurring of genre boundaries (news-media-entertainment) locates the image more broadly within a larger demographic that may otherwise fail to know this story if it were contained only within serious journalism and 
publication media. Furthermore, Soltan's death and image occupy a space of death representation usually dominated by the identification of the hero and public sphere of politics with the male body and masculine subject.

In a matter of days, Soltan's front-page death image was usurped by images of Michael Jackson, including what was touted in the media as his final image. It is an image that also signals the death of media's access to future living images. The final image of Michael Jackson (like all his images) is not by any means his but is governed by copyright and destined to circulate in the public domain regardless of his biological existence.

The constant shift in media attention as key news stories and images replace one another mimics the idea of death as the ceaseless movement of human and individual disappearance and replacement. Critics of the postmodern condition of short memories and attention spans have been concerned with the impact of media culture on collective memory and history: "The past is in danger of becoming a rapidly expanding collection of images, easily retrievable but isolated from time and space, available in an eternal present by pushing a button on the remote control. History thus returns forever-as film." ${ }^{\prime 9}$ Guy Debord identified this postmodern condition as one of a "ceaseless appearance of the important, and almost immediately its annihilation and replacement." ${ }^{10}$

As I have argued elsewhere there is a difference between representations of death, whether real or fictional, and "real-life," up close, embodied experiences of death, and it cannot be assumed that mundane exposure to the former somehow makes the latter experience that much more matterof-fact, unsurprising, or nonconfrontational..$^{11}$ At the same time, in the absence or diminishment of familial or cultural socialization into the "reallife" witnessing of death, representational culture of both real life and fictional or simulated death must play a key role in offering ways of seeing and bearing witness to death.

\section{Screening Death: Between the Real and the Fictional}

In late modernity the apparatus of the camera determines, in the most pervasive way, how and under what circumstances death is seen and not seen, and its uses and effects are not always desirable. The invention of photography and the pervasive presence of the camera in everyday life have created a pornographic view from which sexualized, dead bodies are inspected in detail. The popular television program CSI is the most mainstream in this genre of death pornography. In contrast, Michelangelo Antonioni's 
1966 film Blow-Up critically and self-reflexively represented the relationship between the dead body, the death scene, and the camera. The film explored the nature of perception and misperception through objects and scenes framed by the camera. In the film the recognition of a series of photographs capturing, through different shots, a dead body lying in the grass only very gradually comes to realization. In psychoanalytical terms, the optical unconsciousness has to process the image into conscious recognition gradually. The experience of misrecognition and a politics of not knowing how to see death and the dead body radically contrast with contemporary popular cultural forms such as CSI, where the scientific gaze assumes knowing as a fact of high technology.

The combination of video documentary, webcam, and chatroom has created new types of technologically mediated death scenes. Webcam suicides, streamed live, are perhaps the most ethically troubling to emerge. What does it mean to look at a person dying "for real" on webcam? While simulated or performed death scenes constitute a large part of death culture on the Internet, what is most valued, partly because it is subject to censorship, is real death. Indeed, making the claim of "real" as opposed to simulated death is a feature of Internet marketing and its attentiongrabbing techniques. As Michele White notes, “'Life,' 'live,' and 'real' are used within the webcam genre, as well as other internet settings, in an attempt to make internet representation over into a kind of physical and material reality." 12 In 2007 a forty-two-year-old British man hanged himself on webcam, which was witnessed by one hundred people in a chatroom. It has even been reported that some viewers aggressively encouraged the man to kill himself. In such use of social networking forums one can ask when and at what point witnessing is a form of participation even for those who passively watch without public comment.

In 2008 a nineteen-year-old Florida man, Abraham Biggs, committed suicide by overdosing in front of a staggering audience of fifteen hundred people. I use the word audience because in many respects it was a "show," and an interactive one. Some of the participants in the forum were impatient to see Biggs take the pills and reportedly taunted him on forum postings. Other participants pleaded with him not to go through with it. Biggs had already indicated his intention to die online, telling others on a bodybuilding forum that he would commit suicide that night. He invited them to watch the live video on the "lifecasting" Web site Justin.tv. ${ }^{13}$ Given the large number of people who tuned in, one can imagine that word quickly spread about this event by way of online and offline social networks. Biggs 
also used the Internet to publish a suicide note that contained an apology to his parents. While the video of his suicide was quickly removed from the Internet once it became a police matter, it was, for a period of four hours, a public broadcast. Biggs's live suicide breached rules governing material that network hosts can allow to be seen and archived for continued viewing. In this culture of Internet self-regulation the hosts were viewed as negligent in their duty of care for not monitoring the site and preempting the broadcast by blocking it from going live. In their defense, those monitoring and regulating the site said that they believed it was only a prank. Because they did not monitor the site, the suicide took place, and it took approximately four hours before police came into Biggs's room and were thus in full view on webcam. Indeed, the sight of police on the webcam, cautiously approaching the body of the deceased, could have looked like a scene from the U.S. reality television program Cops. Making this connection reflects the complicated nature of mediated culture, in which real life is decentered and multiplied in its locations as well as cross-referenced by genres and histories of representation. While Jean Baudrillard signaled the death of the real by way of the endless procession of simulacra without origin,${ }^{14}$ it may be more useful to speak of the implosion of representation and reality. In postmodernity, reality is not outside representation or representation outside reality; rather, both constitute an indivisible and irreducible fold. ${ }^{15}$

After Biggs's death, Facebook became a forum for condolence messages and grief blogs. According to media reports, messages were posted on Facebook, begging Biggs to pick up his phone. Thus another technology, the telephone, and by extension, the disembodied voice, rather than a direct face-to-face encounter of speaking, became (for some) the basis for authenticating Biggs's life-or-death status. In an era of online exhibitionism and do-it-yourself reality television, life and death are streamed online. Current generations forge and maintain social relationships online and in view of others. The technological interface does not so much dissolve public and private spheres and boundaries as links them and places people in the lives of others, even those who are physically and geographically distant. As Paul Virilio comments:

We face a duplication of reality. The virtual reality and the "real" reality double the relationship to the real. . . We now have a possibility of seeing at a distance, of hearing at a distance, and of acting at a distance, and this results in a process of de-localization, of the unrooting of the being. "To be" used to mean to be somewhere, to be situated, in the here and now, but the "situation" of the essence of being is undermined by the instantaneity, the imme- 
diacy, and the ubiquity which are characteristic of our epoch. . . From now on, humankind will have to act in two worlds at once. This opens up extraordinary possibilities, but at the same time we face the test of a tearing-up of the being, with awkward consequences. ${ }^{16}$

Ordinary individuals outside corporate, commercial media are transforming through self-production what can be seen and by whom. The death scene broadcast on the Internet and available for viewing in real time in a globally diffuse online "community" raises difficult questions about the actual space of death and the ethics of constructing real-life death as an event for an audience. Real-time webcam death is complex in terms of temporality and spatiality. Through a camera and computer screen a death is taking place "over there" and, in this particular case, in the bedroom of Biggs at the same time that people are watching. It is in an elsewhere, and not geographically located where "I am," but it is also "here" in my space by way of a monitor. At the same time, it is not a one-to-one relationship; it is a network or community of viewers who know each other or at least know of each other's presence and may engage in textual interaction. Thus the Internet is a motivated, multilayered space of (and for) interaction and not a nondialogic or one-way visual regime. While the eye and perspective of the viewer are not seen, it is an inferred presence confirmed by way of log-in and text typing. Contrary to popular readings of disembodiment, the online interface is not entirely disembodied interaction, as images and text activate and mediate sensory and thought processes.

Real-life death streamed on the Web, in comparison to cinematic death, may have less impact emotionally and ethically because a constructed, visualized "interiority" through a camera is not part of the point of view. The medium itself privileges and enacts the value of exteriority and "looking at." Looking on or at death scenes in news media or on the Web is quite different from the experience of death scenes in the mind of a character in a novel, for example, and where entering this "scene" as a psychological process calls to mind the language of witnessing. Film and literature work through much more intense, complex, and multilayered processes of identification through story, character, sound, and image. While cinema and literature tend to construct and mediate interior and exterior relations and perspectives, other means of representing death such as computer games are a play of surfaces. Because cinema and literary fiction deploy multiple perspectives, particularly by constructing or producing access to interiority, the reader/viewer is invariably forced to go through the death of another with all the attendant emotions and pain, rather than as a distant, 
morally indifferent, or ethically disenfranchised spectator. This experience is what Clifton Spargo refers to as the "ethical imagination of fiction" and its demand:

According to the basic contrivance of literary scenes of suffering, the reader stands in the place of a witness in order to be moved by the suffering of another, all the while fortunately aware that the representative scene is a fictive one. Yet few among us, except perhaps for the most rarefied literary readers, could pretend that these scenes having nothing to do with real life and the basic interpersonal problem of whether one can be present in any real way to the other in [his or her] moment of suffering, in [his or her] moment of dying. ${ }^{17}$

The Web has democratized who can speak and what can be said or seen in a deterritorialized, global public sphere. It has also created a concomitant culture of novelty, infamy, and celebrity seeking in the name of entertainment, choice, and freedom. "Life itself," as Neil Gabler suggests, "becomes a movie." 18 The technology of webcams and real time fetishizes "the real," overestimating and overdetermining its revelatory value. Thus it is a question of how representations and technologies approach the unknown, that is, death, as the limit of representation and knowledge.

To shift the focus, one can imagine webcams or interactive video used in quite different types of death scenes, by, for example, enabling family and friends in geographically distant places to monitor the status of dying loved ones and to say goodbye. It is quite imaginable that face-to-face, embodied forms of witnessing the death of a loved one will be supplanted or supplemented by tele-presence. Through the news media camera lens and the webcam, real and simulated images of death and dying are brought close to the eyes and consciousness of the viewer/audience, and yet a relationship to distance is part of the experience. Although technologically mediated and enhanced proximity is designed to overcome the actual corporeal and geographical distance of a representation, there is always a distance effect. The viewer knows that he or she is experiencing proximity as a distance. ${ }^{19}$

\section{Choosing to Die On-Screen}

On February 19, 2009, the New York Times ran a story about Jade Goody, a once unknown British woman from a socially and economically deprived background who entered the fray of media celebrity after her 2002 participation in the globally syndicated reality television program Big Brother. In her early zos, Goody received a diagnosis of cervical cancer while on cam- 
era in the Big Brother household in India. After her diagnosis she remained a constant and seemingly willing subject of media attention, posing for photographs as she went in and out of the hospital for treatment. ${ }^{20}$ Goody's rise to celebrity brought with it her own workout video, perfume, and an autobiography. The total environment and hypervisibility of the Big Brother panopticon prepared Goody for a future of dying on camera. The News of the World bought exclusive rights to film her while she was close to death. Goody explained her agreement by saying: "I've lived in front of the cameras. And maybe I'll die in front of them." ${ }^{21}$ The "maybe" in her statement is an important caveat, enabling her to place herself within the very idea and possibility of dying in front of the camera as an already sufficient marker of crossing boundaries in terms of existing commercial media.

The media's response to Goody's proposed end-of-life event was to draw parallels between the movie The Truman Show (dir. Peter Weir, 1998) and Goody's willingness to translate a fictional scenario into "real life" and biography. ${ }^{22}$ However, this concept and real life are not outside media culture but instead are a complex of representations and genres within it, such that the zone of day-to-day life is either on or off camera but never outside representation. The boundaries between day-to-day life, media news, documentary, and cultural representations are porous, oscillating zones of translation, interpretation, and feedback. This was manifestly evident after the September 11, 2001, destruction of the World Trade Center towers in New York. The imagery of cascading buildings involved a number of translations across cultural forms; they were viewed as scenes from disaster movies (fictional and unreal), and by way of individual cameras were translated into "real-life events" to become also realized fictional events and histories. ${ }^{23}$ The repetition and relay of these images on television was part of the translation process across from cinema-the realm of imagined events and histories - into news media, the realm of real-life events, and histories captured on camera. Goody's death was being talked about, even by Goody herself, as an event within media and popular culture rather than something that has its proper place, first and foremost, outside or beyond it. Already discoursed within The Truman Show Goody's death serves as a realization of the film, as a fiction that became real. In the movie, Truman escapes into real life as he finds a way out of the television set. He escapes his fate of dying in front of the camera on a show about him and named after him. Goody, on the other hand, is constructed in media discourse as someone who is stepping into Truman's fate and realizing the logic of this dystopian narrative. 
Goody's consent to have the final stages of her life filmed and broadcast is morally transgressive as an act of commodification and voyeuristic spectacle in exchange for money. Death, real and fictional, is not outside commercial values and exchange. Still, the idea of a private individual selling his or her end-of-life suffering to a commercial television network is not a common social or media value. Video diaries of people dying, including Farah Fawcett's recent contribution to this genre, while not commercially negotiated products, are not uncommon online and can be found on sites such as YouTube. What marks out Goody's mediated death is that it is situated within the business of commercial media broadcasting and the buying and selling of advertising. The substitution of private for public is partly what gives her death commercial value because it is being exchanged for and against the security of social approval, public scrutiny, disapproval, or moral outrage. The greater the perceived moral divide between social values and media culture, the better chance of commercial and rating success. Thus commercial media success requires the transgression of moral and representational boundaries without then normalizing and undoing the boundary that is the basis of its potential commercial success.

\section{The Inner Death Scene}

Although those who witness the deaths of others cannot know what is actually being experienced or what kind of thought is possible or even occurring, film and literature "imagine" this inner experience by giving it representational form and content. The central tool of the literary death scene is written language, while the cinematic death scene utilizes a number of techniques of representation, where the camera lines up the point of view. Like the literary death scene, the cinematic scene is able to shift and manipulate the point of view, through shots, sequencing, and character focus. In film, a death scene or an impending death can be a device that marks the arc of the plot or the turning point. The death scene in reverse, one that opens the film, is now an iconic structure within the "narrative mortality" of modern cinema. ${ }^{24}$ This is exemplified in films such as Orson Welles's Citizen Kane (1941), Alfred Hitchcock's Rope (1948), Billy Wilder's Sunset Boulevard (1950), and more recently Sam Mendes's American Beauty (1999). Just as Hollywood screenwriter Joe Gillis (played by William Holden) narrates his life in the film Sunset Boulevard after he has been shot dead and is floating in a swimming pool, so does Kevin Spacey's character, Lester, in American Beauty. We are given access to Lester's inner thoughts as he lies on the 
kitchen floor after being shot in the back of the head by his homophobic, gay neighbor. Lester's inner thoughts are represented as a spoken narrative. The scene just before his death shows him picking up a photograph in the kitchen. Delighted by the image, Lester takes it over to the table and sits on a chair gazing at it. The picture is of his daughter's birthday when she was a child, and everyone looks happy and full of life. At that moment a gun is placed at his head and the trigger pulled. The photograph becomes a sequencing device for Lester's own cinematic montage in the split second of his death. Lester's narration of his death is constructed as a lucid moment of self-conscious experience:

I'd always heard your entire life flashes before your eyes the second before you die. First of all, that one second isn't a second at all. It stretches on forever, like an ocean of time. For me it was lying on my back at boys' scout camp watching falling stars. And yellow leaves from the maple trees that lined our street. Or my grandmother's hands and the way her skin seemed like paper. And the first time I saw my cousin Tony's brand-new Firebird. And Janie [as a young woman], and Janie [as a little girl in a fairy costume].... And Carolyn [on a carnival ride].

By internalizing the camera, particularly the moving camera, as a distinctly modern technology of memory formation and memory representation, life is imagined cinematically. Visual narratives order and make possible the ordering of personal or biographical narratives-images going forward or backward in time, from old age to childhood or from childhood to old age. Photo albums, whether material or electronic, are part of this construction of an ordered, sequenced life trajectory that materializes and rehearses the death scene as the conclusion of a visual montage. This particular type of cinematic death scene tells us about how representational technologies shape the cultural imagination, constructing, by way of camera and techniques such as montage, the idea of an interior death scene. Furthermore, what is important about the interior death scene, as part of film history and literature, is its function of filling the void, the empty center where no perspective is possible. By filling the void of death with images or an interior consciousness, film and literature create the impossible scene or nonscene of representation. In analyzing the moment of death and the space of interiority in modern fiction, Robert Detweiler addresses the difficulty and creativity of the representational limit of death:

The author commits himself to a description of the moment [of death] as if within the consciousness of the die-er, yet it is this very consciousness 
that the author must destroy. Not only that; the author also tries to create an emotion which has no foundational objective correlative, since neither he nor the reader has undergone the moment of death that should be the common experience between them. . . This pushing-back of the absolute limits of physical, biological reality by the probing imagination, makes the artist's efforts fascinating and perhaps at last ontologically significant. ${ }^{25}$

The idea or image of an interior death scene is documented in neardeath experience literature. Through historical records and ethnographic research there is now a large catalog of experiences, many of which constitute general knowledge, if not clichés, of the near-death scenography: going toward the light, going through a tunnel toward the light, out-of-body experience, stories of visitations, encounters with menacing figures. Such imagery is documented and debated in a literature with research bases in medicine, studies in religion, and social sciences. Part of this researchbased literature includes the cross-cultural near-death experience investigating the question and impact of culture, religion, and secularization not just on the near-death experience but also the retelling of that experience, how it is put into language. The near-death experience is seductive because its origin is real people, rather than fictional characters, and thus a claim is made on knowing the dying experience, from the inside. Perhaps more interesting than the actual near-death experience itself is the way this phenomenon is a fetish object in religious and scientific worldviews, each seeking to lift the veil and make a claim on the ultimate secret-death itself. The divide between science and religion in near-death experience research and debate (particularly evident in the Journal of Near-Death Studies) is a battleground among biological, materialist, and atheist standpoints and varieties of belief in spirit or soul existence and survival after biological death. This near-death experience also feeds into a collective toolbox of imagery that individuals might draw on in trying to prepare themselves for their own death or the deaths of those they love or bear witness to. ${ }^{26}$

The point of view-how it is constructed and located through the medium of writing or the camera - is an important factor in analyzing this relationship between the dying and their inner death scene (how it appears and feels to them) and those in witness of the dying and thus the death scene as an exterior point of view. Leo Tolstoy's The Death of Ivan Ilyich is a classic representation of the "inner death scene," where the reader is given access to the inner torment of a dying man. The novella is particularly illuminating as it raises the question of when or at what point and for whom the death scene is both present and pronounceable as "here." The story is 
also instructive in terms of thinking about when or what the death scene is before the modern technological era of life and death management. In terms of the narrator's point of view, Ivan Ilyich is within the realm of imminent death long before he is prepared to recognize this for himself. Thus the reader by way of the narrator's point of view recognizes that the protagonist is resisting the obvious explanation for his protracted and increasing painful state of physical and mental health. In this regard, the death scene is not a discrete or unified textual positioning but rather a complex of differing perspectives and psychological orientations. Ivan Ilyich unconsciously knows he is dying, his dreams and intensified suffering tell him so, and yet, at the level of consciousness, he bitterly resists and denies the idea that he is dying until he reaches a final crisis point. Throughout much of the novella there is disjunction or asymmetry between body and mind. Ivan's biological destiny is proceeding with or without his mental and emotional recognition. So the story maps out contrary pathways - the pathway of the body progressing or receding into death, and the mind sometimes following this path but also moving in an opposite direction. Tolstoy's representation of this inner drama is psychoanalytic before there was psychoanalysis. The space of interiority that literature and film carves out constructs the scene of death within absence-an absence not correlated to presence.

The death scene in literature and film, although varied and diverse, can construct a sensibility and structure of feeling sensitive and empathic to the dying of others. An extraordinary example of such a death scene is in the film Into the Wild (dir. Sean Penn, 2007). Like Midnight Cowboy (dir. John Schlesinger, 1969) it is a story of death framed within an American ethos (though not solely American). In this case, it is the ethos of masculine independence and the ideal of an unmediated self-to-self relationship and authentic existence in nature. The central character of the film, Christopher McCandless, dies in isolation, without human witness, in the wildness of Alaska after consuming a food that he later realizes is poisonous. After days of tremendous physical and psychological suffering, McCandless prepares himself for death by washing, dressing, and lying down on the mattress in the bus where he lives. He dies in solitude, looking at the face of the moon. It is impossible to escape this scene, to withdraw or shift attention from it. And it is significant that it is brought to us by way of cinema.

Western civilization partly identifies its civilizing process and progress through the sequestering of death from immediate viewing and witnessthe absence of public executions, the government and management of unforeseen death in public spaces by policing and human services, the 
removal and displacement of the cemetery outside the city into what Michel Foucault and Jay Miskowiec call "other spaces," ${ }^{27}$ the management and privatization of the dying process within medical settings. The more immediate public face of death has been replaced by a mediated, spatially mobile culture of seeing and witnessing death. We look at death, both real and simulated, through printed images and televisual screens (televisions, computers, phones) in both private and public settings. Our thirst for knowledge about death - to know what it is like to die-seems to have no limits. And yet a good deal of death imagery does not address or even face the question of mortality. Indeed, the saturation of death imagery in both our media and our mediated cultural condition may be a way of actively screening out or covering a contemplative, politically and ethically generative, thoughtful process and consciousness toward mortality-our own and that of others.

\section{Notes}

1 Stjepan Meštrović, Postemotional Society, trans. David Riesman (London: Sage, 1997).

2 A television drama death might elicit greater emotion and empathy than a news story of famine because the former is framed by a complex array of visual, sound, and narrative accoutrements designed to elicit processes of identification and emotional impact. The latter is also a passing story and image in a larger complex of media stories, while the former is a longer, self-contained narrative enabling concentrated engagement on the part of the viewer or reader.

3 Philippe Aries, “The Reversal of Death: Changes in Attitudes toward Death in Western Societies," American Quarterly 26.5 (1974): 540.

4 Ibid., 539.

5 "10 Hot Pics," Who Weekly, July 6, 2009.

6 Ibid.

7 The use of the slang pics trivializes the subject matter of Soltan's death, further placing it on an equal footing with all the other images.

8 Fredric Jameson, "Postmodernism, or The Cultural Logic of Late Capitalism," New Left Review, no. 146 (July-August 1984): 58.

9 Anton Kaes, From Hitler to Heimat: The Return of History as Film (Cambridge, MA: Harvard University Press, 1989), 198.

10 Debord quoted in Jonathan Crary, "Spectacle, Attention, Counter-Memory," October 50 (1989): 106.

See Margaret Gibson, "Death and Mourning in Technologically Mediated Culture," Health Sociology Review 16.5 (2007): 415-24.

Michele White, "Too Close to See: Men, Women, and Webcams," New Media and Society $5.1(2003): 18$.

13 Paul Thompson, "Teenager Commits Suicide Live Online while 1,500 People Watch Video Stream," Daily Mail, November 21, 2008, www.dailymail.co.uk/news/worldnews/ article-1088173/Teenager-commits-suicide-live-online-1-500-people-watch-videostream.html. 
Jean Baudrillard, "Simulacra and Simulations," in Jean Baudrillard: Selected Writings, ed. Mark Poster (Stanford, CA: Stanford University Press, 1988), 166-84.

While not explicitly taking up Gilles Deleuze's concept of the fold outlined in his work on Michel Foucault and Gottfried Leibniz, my usage resonates with his idea of the inside as nothing more than the fold of the outside. Gilles Deleuze (1988), Foucault, trans. Sean Hand (Minneapolis: University of Minnesota Press, 1988); and Deleuze, The Fold: Leibniz and the Baroque, trans. Tom Conley (Minneapolis: University of Minnesota Press, 1993).

16 Carlos Oliveira, "Global Algorithm 1.7: The Silence of the Lambs: Paul Virilio in Conversation," trans. Patrice Riemens, CTheory (1996).

17 R. Clifton Spargo, The Ethics of Mourning: Grief and Responsibility in Elegiac Literature (Baltimore: Johns Hopkins University Press, 2004), 3.

18 Neil Gabler, Life the Movie: How Entertainment Conquered Reality (New York: Knopf, 1998), 4 .

19 Gibson, "Death and Mourning," 417.

20 Goody's initial appearance in Big Brother earned her a spot in the Indian version of the show (an outcome of her racist remarks about an Indian participant in the first Big Brother, which notched up her notoriety). These two previous appearances were sufficient to make her a candidate for Celebrity Big Brother.

Sarah Lyall, "Squirming, but Watching a Dying Reality Star," New York Times, February 19, 2009, www.nytimes.com/2009/02/20/world/europe/2obritain.html.

See Hadley Freeman, "Harsh Reality," Guardian, February 5, 2009, www.guardian.co .uk/lifeandstyle/2009/feb/05/jade-goody-celebrity-big-brother; and "The Truman Show and Jade Goody," What's on TV, March 3, 2009, http://whatsontv.co.uk/blogs/movietalk/ 2009/03/03/the-truman-show-and-jade-goody/.

23 See Barbara Kirshenblatt-Gimblett, "Kodak Moments, Flashbulb Memories: Reflections on 9/11," Drama Review 47.1 (2003): 11-48.

24 Catherine Russell, Narrative Mortality: Death, Closure, and New Wave Cinemas (Minneapolis: University of Minnesota Press, 1995).

25 Robert Detweiler, "The Moment of Death in Modern Fiction," Contemporary Literature 13.3 (1972): 271-72.

26 The near-death experience became a focused object of scientific inquiry and research in the 1970 s and has come to mark a dividing line between religious and scientific explanation of its causes and meaning. Religious interpretations see it as evidence of a spirit existing and surviving beyond the body, and science sees it as a psychotropic phenomenon caused by systemic responses in the brain.

27 Michel Foucault and Jay Miskowiec, "Of Other Spaces," Diacritics 16.1 (1986): 22-27. In this essay, Foucault and Miskowiec discuss the transformation of social practices and attitudes toward the dead and the burial site of the cemetery. Through the rise of medicine and science, the dead became associated with images and issues of illness and disease. It became necessary, they argue, to delineate geographically and psychologically the spaces of the living from those of the dead. The dead once at the heart of the city are now removed to the outside of "living sites" and places - the cemetery becomes another city, an "other space," and this part of the modernist project of the sequestering of death. 